\title{
A Critical Review on Breast Cancer Literature: Screening, Awareness and Preventive Measures
}

\author{
Ms. M. Swapana \\ Research Scholar, VIT Business School, VIT University, Vellore, India - 632014 \\ Email Id: shalluma55@gmail.com \\ Dr. C. Padmavathy \\ Assistant Professor (Senior), VIT Business School, VIT University, Vellore, India - 632014 \\ Email ld: cpadma85@gmail.com
}

\section{Doi:10.5901/mjss.2015.v6n4s3p256}

\section{Abstract}

Breast cancer has become the most common cancer diagnosed in women. This paper reviews key literature on breast cancer covering various aspects including breast cancer and self-examination, awareness level of breast cancer among women, psychological stress of breast cancer patients, causes of breast cancer and preventive measures for breast cancer. This paper sheds light to urban and young women that self-screening is one of the important yardsticks to prevent late diagnosis of breast cancer and after-math of breast cancer treatment.

Keywords: Breast cancer, awareness, screening, symptoms, risk, preventive measures, India

\section{Introduction}

Breast cancer, the most common non-skin cancer, is now ranked as the first among all cancers diagnosed in women (Kolahdoozan, Sadjadi, Radmard, \& Khademi, 2010). It accounts for over $10 \%$ of all cancers among women worldwide (Bray, McCarron, \& Parkin, 2004) which in turn causes the most frequent cause of cancer death in women in both developing and developed regions (Jacques Ferlay et al., 2010).

Breast cancer has been growing in a rapid manner with nearly one million new cases each year (Maxwell Parkin, Bray, Ferlay, \& Pisani, 2001). One of the recent studies stated that, more than half (52.9\%) of 1.67 million new breast cancer cases were diagnosed particularly in developing countries and as an evidence, nearly $62 \%$ of deaths occurred in developing countries due to the effect with breast cancer in 2012 (J. Ferlay et al., 2013). It must be noted that mortality rate of breast cancer is comparatively less in high-income countries than low and middle income countries (Jacques Ferlay et al., 2010)

In India, young women who are relatively at the premenopausal stage are very much stricken to the effect of breast cancer (Sandhu, Sandhu, Karwasra, \& Marwah, 2010). At the same time, Asian Indian women specifically who immigrate to the United States have higher breast cancer rates when compared to their corresponding place in India (Smyer \& Stenvig, 2007). Moreover, as an effect of lifestyle factors, the incidence of breast cancer is higher among women in urban areas than among who lives in rural regions (Bao \& Davidson, 2007). Despite of the promising survival rates, breast cancer leads to the most harmful side effects like loss of breast(s), deformities in the breast(s), tissue damage, decreased range of motion, muscle loss/weakness, and weight gain, etc (K. K. Collins et al., 2011) which provokes a major stress among women (Compas \& Luecken, 2002). Therefore, the purpose of this research is to review literature on breast cancer that creates awareness, screening and preventive measures of breast cancer.

\section{Review of Literature}

In general, Cancer is a disease that largely affects the quality of life of the people (Cohen, 2000). Breast cancer is more hazardous among all other cancers which entails the five-year survival rate of about $85 \%$ and the ten-year for $71 \%$ (Imaginis, 2005), however, early detection and effective treatment can lead to improved survival rate of breast cancer patients (American Cancer Society, 2014). Screening helps in early detection of breast cancer as it is related to the 
perceptions of risk, benefit, and barriers through a reasoning process, but it is said that breast cancer screening techniques are underused (Carter, Park, Moadel, Cleary, \& Morgan, 2002; Schootman \& Jeffe, 2003). However, screening participation will be effective in influencing breast cancer death only if the screening examination is performed in the stage when the breast cancer is detectable on the mammogram (Weiss, 2011).

More than $90 \%$ of breast cancer patients seek medical attention only at advanced stages (Mohiuddin et al., 2012; Story et al., 2012) and in consequence almost all breast cancer cases are detected clinically. There are many screening methods like mammogram, breast self-examination, etc., which helps people in early detection but about $77 \%$ of the people were unaware of breast cancer screening methods (Özaras, Durualp, Civelek, Gül, \& Ünsal, 2010). To be noted, lack of knowledge about how to detect the disease at an early stage would potentially lead to misconceptions regarding its curability and the effectiveness of early detections (Dandash \& Al-Mohaimeed, 2007).

\subsection{Breast Cancer Symptoms}

As a defensive measure, women should know how their breast(s) normally feel. There are many primary symptoms like insomnia, diarrhoea, constipation, loss of taste, fatigue, vomiting, and pain that indicates the existence of breast cancer (Chie, Chang, Huang, \& Kuo, 2003; Peintinger, Reitsamer, Stranzl, \& Ralph, 2003; Zotti et al., 2000). In addition to common symptoms like breast symptoms, discomfort due to hair loss or, arm symptoms, there are several dissimilarities in functional aspects like expectations for future, sexual functionality, and sexual satisfaction as well (G.C., S., B.M., D., \& J., 2001; Zhao \& Kanda, 2000).

All these changes would likely affect women's valuation of their bodies (Fobair et al., 2006; Helms, O'Hea, \& Corso, 2008) and experience poor body image and body dissatisfaction (Chen, Liao, Chen, Chan, \& Chen, 2012), which may continue for years following diagnosis and treatment (Falk Dahl, Reinertsen, Nesvold, Fossa, \& Dahl, 2010). The adaptation of a western lifestyle such as dietary, hormonal determinants and the like paves the way for increase in breast cancer occurrence among Asian and Asian American women (Maxwell Parkin et al., 2001).

\subsection{Breast Cancer Risk}

In India, premenopausal women constitute about 50\% of all breast cancer patients (Khokhar, 2012). The risk for premenopausal breast cancer is highly evident because of the causal link between cigarette smoking at a young age (Bjerkaas et al., 2013; Dossus et al., 2014; Glantz \& Johnson, 2014). Looking into the breast cancer arrival in postmenopausal stage, dietary fat and a higher body mass index are subject to increase in the risk (MacMahon, 2006). Further, there are several reproductive and non-reproductive factors like first pregnancy, breastfeeding, parity and menopausal hormone therapy, body mass index, alcohol intake family history of cancer, respectively has been noted to have related with the risk of breast cancer (Ban \& Godellas, 2014).

Even there is an increase in number of pregnancy-associated breast cancer (Smith, Dalrymple, Leiserowitz, Danielsen, \& Gilbert, 2001) which arises because of personal history of breast cancer, family history of breast cancer, advanced maternal age, increased consumption of alcohol, and a sedentary lifestyle (American Cancer Society \& Society, 2013). However, termination of pregnancy does not ensure survival of the patient and it is of no use to cancer therapy, rather, breast lumps should undergo immediate consultation during pregnancy or lactation in order to reduce the risk factors (Helewa et al., 2002). Men should be given proper knowledge about breast cancer so that they can have the potential to understand the effects of the breast cancer and provide essential support when his partner or relative develops the syndrome (McMenamin et al., 2005).

Breast cancer arousal has been shown to be higher in women of higher socio-economic groups than the women with lower average social status (Shack, Jordan, Thomson, Mak, \& Møller, 2008) has been known by establishing the relationship between the risk of breast cancer and socio-economic status (Kurkure \& Yeole, 2006).

Also it should be noted that despite of common known factors like age, family history, etc., breast size is one of the major independent risk factor denotes breast cancer (Stuckey, 2011). Also, brassiere use was measured as a risk factor in the study conducted by Hsieh \& Trichopoulos, (1991). In a recent study, it is found that Cup size was a strong predictor of breast cancer mortality by taking a sample of 79,124 women (Williams, 2013). Bottorff et al., (2010), reported that tobacco exposure is the one that highly accounts for the risk of breast cancer.

\subsection{Breast Cancer Consequences}

In the face of a growing body of literature on health beliefs and health education, there are several studies that are 
concerned with breast cancer (Bowling, 1996). One among those studies found that women diagnosed with breast cancer and undergoing treatment experience psychological distress (David, Montgomery, Macavei, \& Bovbjerg, 2005). Breast loss is the major cause for psychological distress in women who has been treated for breast cancer (Costanzo et al., 2007). Even it is measured and found that there is a correlation between women risk perception and worry about breast cancer (V. Collins, Halliday, Warren, \& Williamson, 2000; Lipkus et al., 2000). Some previous studies reported that inconvenience, embarrassment, worry, fear, etc., are the top most reasons for hesitation of undergoing screening activities.

Coping strategy is the best that is strongly associated with adjustment and functioning of breast cancer patients as well as with emotional distress in recurrent patients (Cohen, 2002; Kershaw, Northouse, Kritpracha, Schafenacker, \& Mood, 2004). Age and language ability also plays a significant role in predicting health status among immigrant women (Landrine \& Klonoff, 2004). For example, it is proved that women with better language ability were more likely to obtain breast examinations (O'Malley, Kerner, Johnson, \& Mandelblatt, 1999).

\subsection{Preventive Measures}

However, breast cancer patients can attain benefit in a number of ways where breast implant is the topmost measure to cure the controversy of breast cancer (Deapen, Hirsch, \& Brody, 2007). It would be even easier, if they undergo the prescribed exercise properly during treatment (Courneya et al., 2007).

There is another study that nourishes the relationship between vegetable consumption and the breast cancer risk (Shannon et al., 2005). Also, there are some specifications about the vegetable intake like dark yellow types (Malin et al., 2003), cruciferous (Terry, Terry, \& Wolk, 2001), tomatoes (Min, Sang, Jung, Pa, \& Min, 2007) and broccoli (Joseph et al., 2004) that would reduce the risk of breast cancer. No other dietary factors have been related to the risk of breast cancer either in pre or postmenopausal women (World Cancer Research Fund, 2007).

\subsection{Breast Cancer Screening}

Screening is the boon for breast cancer patients ever which helps in diagnosing the breast cancer even before it occurs symptomatically (Bleyer \& Welch, 2012). The trials of screening strategies works well in indicating how screening saved lives along with the statement of overdiagnosis harmfulness (Gøtzsche, 2012). The population based approach for implementation of breast cancer screening is recommended as it aims to give each eligible individual an equal chance of getting benefited from with effective quality assurance (Lynge, Törnberg, Von Karsa, Segnan, \& Van Delden, 2012). Screening invitations is limited to women who are more than 50 years of age especially in European countries(Giordano et al., 2012). Most of the people especially the Arab Muslims perceive that the absence of symptoms and signs for indicating good health which makes them to deny the progression of early detection of breast cancers (Donnelly et al., 2013).

The major screening strategies considered in this study are mammography, Breast Self Examination (BSE), and Clinical Breast Examination (CBE). These strategies help in identifying tumour. Speaking of which Mammography screening is the best method of screening which helps in early detection that reduces the breast-cancer mortality rates (Glasziou \& Houssami, 2011; Marmot et al., 2013; Uk \& Cancer, 2012). Mammography is the most efficient way since it helps in diagnosing cancer at the asymptomatic stage. Say, when a breast cancer is identified in a asymptomatic stage the chance of treating in a positive direction is more. For instance, a recent study found that mammography screening reduces the mortality of breast cancer by an estimated fifteen percentage (Drukteinis, Mooney, Flowers, \& Gatenby, 2013). There is a necessity for investigating various methods to explore the quality and benefits of mammography screening (Autier, Esserman, Flowers, \& Houssami, 2012).

The newest improvement in mammography screening is called 'Tomosynthesis' which came into practice to improve acceptance. It is especially helpful for the women who possess dense breasts. The major advantage of this tomosynthesis is lower recall rates and it also facilitates slight increase in cancer detection (Haas et al., 2013). Mammography screening has grown a step forward from plain-film to digital mammography. With the implementation digital mammography higher test sensitivity for women aged fifty years and women with dense breasts has been experienced (Bluekens, Holland, Karssemeijer, Broeders, \& den Heeten, 2012).

Breast Self Examination is something where women need to go for examining their breasts once in every month (Shin et al., 2012). The estimation of sensitivity and specificity during BSE have experienced growth (Suh, Atashili, Fuh, \& Eta, 2012) but however study conducted by Hackshaw \& Paul, (2003) concluded that BSE is not efficient in reducing the mortality rate since there is no huge variation in mortality rates of those who practiced or undergone BSE. Looking deeply 
it is quite an inexpensive strategy which is associated more with women who seeks medical care.

Clinical breast exam is the process of examining the breasts with the help of clinicians. Efficiency of examination of breasts by health professional is highly influenced by three major concerns like training and skills of the consultant, age of the woman, and size of tumour. CBE is very much effective in laying positive predictive value (Shahnazi \& Khalili, 2010).

The awareness and exercising of mammography screening was slightly higher in urban women when compared to the their rural counterparts (Leung, McKenzie, Martin, Dobson, \& McLaughlin, 2014). It is because of the reasons like mobile access, awareness campaigns, education system, etc, (McDonald \& Sherman, 2010). The most common reason for women for being not able to participate in screening activities is the inability of speaking English or French. On the other hand women in remote areas have only limited access to alternatives and hence they just simply prefer dropping out the system which they feel as hostile rather than dealing with it. (Todd \& Stuifbergen, 2012). Another reason for people for neglecting screening is related to the lack of physician recommendation (Othman et al., 2013).

It is necessary to create awareness so as to ensure a better screening of breast cancer (Fallowfield, 1995). For instance, creating awareness about early detection and screening practices by designing educational programs at the high school and college levels that will instil in young women (Shin, Park, \& Kim, 2012). Luker, et al., (1996), also found that women with breast cancer sought and paid attention to information from medical books and journals. Another efficient way of disseminating information is targeting the mothers of young daughters and conveying the messages about adolescent breast cancer risk reduction, since they are the primary caretakers of children (Janicke \& Finney, 2003). It also helps in making precautions among young girls at a very early stage (Adzersen, Jess, Freivogel, Gerhard, \& Bastert, 2003).

Information plays a vital role in influencing the decision making of women with breast cancer (Luker et al., 1995). It is due to the fact that well informed women would take a better decision which ensures their health and well being (ACS, 2012). It is made easier, that preventive measures about all health issues including breast cancer in available online and since anyone with access to the internet can now obtain information instantaneously and interact with online discussions and content and make use of it in order to make avail effective treatment (Chou, Prestin, Lyons, \& Wen, 2013).

\section{Conclusion}

People need to understand that early detection of breast cancer save thousands of lives each year. Moreover it is advisable to seek help from the health providers for taking advantage of the screening tests (American Cancer Society, 2011). Several studies that has been conducted in high income; low- and middle income countries have shown that patients of breast cancer and their corresponding families are in need of physical and psychosocial supportive care during their treatment (Schmid-Buchi, Halfens, Muller, Dassen, \& van den Borne, 2013).

It is not that a person is having breast cancer for taking a screening test. It is unpredictable that whether an individual can benefit from screening or land in having treatment. However the notion here is if a person chose to undergo screening he or she has the chance of having their life extended with some consequences but if not so they are meant to be risking their life as whole as a result of lack of early detection. Thus, doing so, (i.e., breast cancer screening) will lead to a long term positive health implication as once started in a early age it will continue into adulthood and even throughout life (Ludwick \& Gaczkowski, 2001). Practitioners need to provide evocative counselling about the breast cancer collectively progressed from personal experience and outside sources to increase the awareness level of early detection through proper screening of breast cancer (Wright et al., 2015).

\section{References}

ACS. (2012). Breast Cancer Early Detection The importance of finding breast cancer. doi:http://www.cancer.org/acs/groups/cid/ documents/webcontent/003165-pdf.pdf

Adzersen, K. H., Jess, P., Freivogel, K. W., Gerhard, I., \& Bastert, G. (2003). Raw and cooked vegetables, fruits, selected micronutrients, and breast cancer risk: A case-control study in Germany. Nutrition and Cancer-An International Journal, 46(2), 131-137.

American Cancer Society. (2014). Cancer Facts \& Figures. Cancer Facts and Figures. Retrieved from http://www.cancer.org/acs/groups/ content/@research/documents/webcontent/acspc-042151.pdf

American Cancer Society, \& Society, A. C. (2013). Cancer Facts \& Figures 2013. American Cancer Society (Vol. 2010).

Autier, P., Esserman, L. J., Flowers, C. I., \& Houssami, N. (2012). Breast cancer screening: the questions answered. Nature Reviews Clinical Oncology. doi:10.1038/nrclinonc.2012.126

Ban, K. A., \& Godellas, C. V. (2014). Epidemiology of Breast Cancer. Surgical Oncology Clinics of North America. doi:10.1016/j.soc.2 014.03.011 
Bao, T., \& Davidson, N. E. (2007). Adjuvant endocrine therapy for premenopausal women with early breast cancer. Breast Cancer Research : $B C R, 9(6), 115$. doi:10.1186/bcr1830

Bjerkaas, E., Parajuli, R., Weiderpass, E., Engeland, A., Maskarinec, G., Selmer, R., \& Gram, I. T. (2013). Smoking duration before first childbirth: An emerging risk factor for breast cancer? Results from 302,865 Norwegian women. Cancer Causes and Control, 24(7), 1347-1356. doi:10.1007/s10552-013-0213-1

Bleyer, A., \& Welch, H. G. (2012). Effect of three decades of screening mammography on breast-cancer incidence. The New England Journal of Medicine, 367(21), 1998-2005. doi:10.1056/NEJMoa1206809

Bluekens, A. M. J., Holland, R., Karssemeijer, N., Broeders, M. J. M., \& den Heeten, G. J. (2012). Comparison of Digital Screening Mammography and Screen-Film Mammography in the Early Detection of Clinically Relevant Cancers: A Multicenter Study. Radiology. doi:10.1148/radiol.12111461

Bottorff, J. L., McKeown, S. B., Carey, J., Haines, R., Okoli, C., Johnson, K. C., ... Ptolemy, E. (2010). Young women's responses to smoking and breast cancer risk information. Health Education Research, 25(4), 668-677. doi:10.1093/her/cyp067

Bowling, A. (1996). Modern Medicine: Lay Perspectives and Experiences. BMJ. doi:10.1136/bmj.312.7042.1368a

Bray, F., McCarron, P., \& Parkin, D. M. (2004). The changing global patterns of female breast cancer incidence and mortality. Breast Cancer Research : BCR, 6(6), 229-239. doi:10.1186/bcr932

Carter, J., Park, E. R., Moadel, A., Cleary, S. D., \& Morgan, C. (2002). Cancer knowledge, attitudes, beliefs, and practices (KABP) of disadvantaged women in the South Bronx. Journal of Cancer Education: The Official Journal of the American Association for Cancer Education, 17(3), 142-149.

Chen, C.-L., Liao, M.-N., Chen, S.-C., Chan, P.-L., \& Chen, S.-C. (2012). Body image and its predictors in breast cancer patients receiving surgery. Cancer Nursing, 35(5), E10-6. doi:10.1097/NCC.0b013e3182336f8b

Chie, W. C., Chang, K. J., Huang, C. S., \& Kuo, W. H. (2003). Quality of life of breast cancer patients in Taiwan: Validation of the Taiwan Chinese version of the EORTC QLQ-C30 and EORTC QLQ-BR23. Psycho-Oncology, 12(7), 729-735. doi:10.1002/pon.727

Chou, W. Y. S., Prestin, A., Lyons, C., \& Wen, K. Y. (2013). Web 2.0 for health promotion: Reviewing the current evidence. American Journal of Public Health. doi:10.2105/AJPH.2012.301071

Cohen, M. (2002). Coping and emotional distress in primary and recurrent breast cancer patients. Journal of Clinical Psychology in Medical Settings. Retrieved from http://ovidsp.ovid.com/ovidweb.cgi?T=JS\&PAGE=reference\&D=psyc4\&NEWS=N\&AN=200215959-008

Collins, K. K., Liu, Y., Schootman, M., Aft, R., Yan, Y., Dean, G., ... Jeffe, D. B. (2011). Effects of breast cancer surgery and surgical side effects on body image over time. Breast Cancer Research and Treatment, 126(1), 167-176. doi:10.1007/s10549-010-10777

Collins, V., Halliday, J., Warren, R., \& Williamson, R. (2000). Cancer worries, risk perceptions and associations with interest in DNA testing and clinic satisfaction in a familial colorectal cancer clinic. Clinical Genetics, 58(6), 460-468. doi:10.1034/j.13990004.2000.580606.x

Compas, B. E., \& Luecken, L. (2002). Psychological adjustment to breast cancer. Current Directions in Psychological Science, 11(3), 111-114. doi:10.1111/1467-8721.00180

Costanzo, E. S., Lutgendorf, S. K., Mattes, M. L., Trehan, S., Robinson, C. B., Tewfik, F., \& Roman, S. L. (2007). Adjusting to life after treatment: distress and quality of life following treatment for breast cancer. British Journal of Cancer, 97(12), 1625-1631. doi:10.1038/sj.bjc.6604091

Courneya, K. S., Segal, R. J., Mackey, J. R., Gelmon, K., Reid, R. D., Friedenreich, C. M., .. McKenzie, D. C. (2007). Effects of aerobic and resistance exercise in breast cancer patients receiving adjuvant chemotherapy: a multicenter randomized controlled trial. Journal of Clinical Oncology: Official Journal of the American Society of Clinical Oncology, 25(28), 4396-4404. doi:10.1200/JCO.2006.08.2024

Dandash, K. F., \& Al-Mohaimeed, A. (2007). Knowledge, attitudes, and practices surrounding breast cancer and screening in female teachers of buraidah, saudi arabia. International Journal of Health Sciences, 1(1), 61-71.

David, D., Montgomery, G. H., Macavei, B., \& Bovbjerg, D. H. (2005). An empirical investigation of Albert Ellis's binary model of distress. Journal of Clinical Psychology, 61(4), 499-516. doi:10.1002/jclp.20058

Deapen, D. M., Hirsch, E. M., \& Brody, G. S. (2007). Cancer risk among Los Angeles women with cosmetic breast implants. Plastic and Reconstructive Surgery, 119(7), 1987-1992. doi:10.1097/01.prs.0000260582.23971.02

Donnelly, T. T., Al Khater, A.-H., Al-Bader, S. B., Al Kuwari, M. G., Al-Meer, N., Malik, M., .. Fung, T. (2013). Beliefs and attitudes about breast cancer and screening practices among Arab women living in Qatar: a cross-sectional study. BMC Women's Health, 13, 49. doi:10.1186/1472-6874-13-49

Dossus, L., Boutron-Ruault, M.-C., Kaaks, R., Gram, I. T., Vilier, A., Fervers, B., ... Clavel-Chapelon, F. (2014). Active and passive cigarette smoking and breast cancer risk: results from the EPIC cohort. International Journal of Cancer. Journal International Du Cancer, 134(8), 1871-88. doi:10.1002/ijc.28508

Drukteinis, J. S., Mooney, B. P., Flowers, C. I., \& Gatenby, R. a. (2013). Beyond mammography: new frontiers in breast cancer screening. The American Journal of Medicine, 126(6), 472-9. doi:10.1016/j.amjmed.2012.11.025

Falk Dahl, C. A., Reinertsen, K. V, Nesvold, I. L., Fossa, S. D., \& Dahl, A. A. (2010). A study of body image in long-term breast cancer survivors. Cancer, 116, 3549-3557. doi:10.1002/cncr.25251

Fallowfield, L. J. (1995). Assessment of quality of life in breast cancer. Acta Oncologica (Stockholm, Sweden), 34(5), 689-694.

Ferlay, J., Shin, H.-R., Bray, F., Foreman, D., Mathers, C., \& Parkin, D. M. (2010). GLOBOCAN 2008 v1.2, Cancer Incidence and 
Mortality Worldwide: IARC CancerBase No. 10 [Internet]. Retrieved from http://globocan.iarc.fr

Ferlay, J., Soerjomataram, I., Ervik, M., Dikshit, R., Eser, S., Mathers, C., ... Bray, F. (2013). GLOBOCAN 2012 v1.0, Cancer Incidence and Mortality Worldwide: IARC CancerBase. No. 11 [Internet].

Fobair, P., Stewart, S. L., Chang, S., D'Onofrio, C., Banks, P. J., \& Bloom, J. R. (2006). Body image and sexual problems in young women with breast cancer. Psycho-Oncology, 15(7), 579-594. doi:10.1002/pon.991

G.C., N., S., S., B.M., S., D., K., \& J., C. (2001). Quality of life in breast cancer patients: A cluster analytic approach. Journal of Exposure Analysis and Environmental Epidemiology, 11(4), 269-278. Retrieved from http://ovidsp.ovid.com/ovidweb.cgi?T=JS\&PAGE= reference $\& D=e m e d 5 \& N E W S=N \& A N=2001333670$

Giordano, L., von Karsa, L., Tomatis, M., Majek, O., de Wolf, C., Lancucki, L., ... Ponti, A. (2012). Mammographic screening programmes in Europe: organization, coverage and participation. Journal of Medical Screening. doi:10.1258/jms.2012.012085

Glantz, S. A., \& Johnson, K. C. (2014). The surgeon general report on smoking and health 50 years later: Breast cancer and the cost of increasing caution. Cancer Epidemiology Biomarkers and Prevention. doi:10.1158/1055-9965.EPI-13-1081

Glasziou, P., \& Houssami, N. (2011). The evidence base for breast cancer screening. Preventive Medicine, 53(3). doi:10.1016/j. ypmed.2011.05.011

Gøtzsche, P. C. (2012). Mammography screening: truth, lies, and controversy. The Lancet. doi:10.1016/S0140-6736(12)61216-1

Haas, B. M., Kalra, V., Geisel, J., Raghu, M., Durand, M., \& Philpotts, L. E. (2013). Comparison of tomosynthesis plus digital mammography and digital mammography alone for breast cancer screening. Radiology, 269(3), 694-700. doi:10.1148/radiol. 13130307

Hackshaw, A. K., \& Paul, E. A. (2003). Breast self-examination and death from breast cancer: a meta-analysis. British Journal of Cancer, 88(7), 1047-1053. doi:10.1038/sj.bjc.6600847

Helewa, M., Lévesque, P., Provencher, D., Lea, R. H., Rosolowich, V., \& Shapiro, H. M. (2002). Breast cancer, pregnancy, and breastfeeding. Journal of Obstetrics and Gynaecology Canada : JOGC = Journal D'obstétrique et Gynécologie Du Canada : JOGC, 24(2), 164-80; quiz 181-4. Retrieved from http://www.ncbi.nlm.nih.gov/pubmed/12196882

Helms, R. L., O'Hea, E. L., \& Corso, M. (2008). Body image issues in women with breast cancer. Psychology, Health \& Medicine, 13(3), 313-325. doi:10.1080/13548500701405509

Hsieh, C. C., \& Trichopoulos, D. (1991). Breast size, handedness and breast cancer risk. European Journal of Cancer, 27(2), 131-135. doi:10.1016/0277-5379(91)90469-T

Janicke, D. M., \& Finney, J. W. (2003). Children's Primary Health Care Services: Social-Cognitive Factors Related to Utilization. Journal of Pediatric Psychology, 28(8), 547-557. doi:10.1093/jpepsy/jsg045

Joseph, M. A., Moysich, K. B., Freudenheim, J. L., Shields, P. G., Bowman, E. D., Zhang, Y., ... Ambrosone, C. B. (2004). Cruciferous vegetables, genetic polymorphisms in glutathione S-transferases M1 and T1, and prostate cancer risk. Nutrition and Cancer, 50(2), 206-213. doi:10.1207/s15327914nc5002_11

Kershaw, T., Northouse, L., Kritpracha, C., Schafenacker, A., \& Mood, D. (2004). Coping strategies and quality of life in women with advanced breast cancer and their family caregivers. Psychology \& Health. doi:10.1080/08870440310001652687

Khokhar, A. (2012). Breast cancer in india: Where do we stand and where do we go? Asian Pacific Journal of Cancer Prevention. doi:10.7314/APJCP.2012.13.10.4861

Kolahdoozan, S., Sadjadi, A., Radmard, A. R., \& Khademi, H. (2010). Five common cancers in Iran. Archives of Iranian Medicine. doi:0011 [pii]|r010132/AIM.0011 [pii]

Kurkure, A. P., \& Yeole, B. B. (2006). Social inequalities in cancer with special reference to South Asian countries. Asian Pacific Journal of Cancer Prevention : APJCP, 7(1), 36-40.

Landrine, H., \& Klonoff, E. A. (2004). Culture change and ethnic-minority health behavior: An operant theory of acculturation. Journal of Behavioral Medicine. doi:10.1007/s10865-004-0002-0

Leung, J., McKenzie, S., Martin, J., Dobson, A., \& McLaughlin, D. (2014). Longitudinal patterns of breast cancer screening: mammography, clinical, and breast self-examinations in a rural and urban setting. Women's Health Issues : Official Publication of the Jacobs Institute of Women's Health, 24(1), e139-46. doi:10.1016/j.whi.2013.11.005

Lipkus, I. M., Kuchibhatla, M., McBride, C. M., Bosworth, H. B., Pollak, K. I., Siegler, I. C., \& Rimer, B. K. (2000). Relationships among breast cancer perceived absolute risk, comparative risk, and worries. Cancer Epidemiology Biomarkers and Prevention, 9(9), 973-975.

Ludwick, R., \& Gaczkowski, T. (2001). Breast self-exams by teenagers: outcome of a teaching program. Cancer Nursing, 24(4), 315319. doi:10.1097/00002820-200108000-00013

Luker, K. A., Beaver, K., Leinster, S. J., \& Owens, R. G. (1996). Information needs and sources of information for women with breast cancer: a follow-up study. Journal of Advanced Nursing, 23(3), 487-495. doi:10.1111/j.1365-2648.1996.tb00010.x

Luker, K. A., Beaver, K., Leinster, S. J., Owens, R. G., Degner, L. F., \& Sloan, J. A. (1995). The information needs of women newly diagnosed with breast cancer. Journal of Advanced Nursing, 22(1), 134-141.

Lynge, E., Törnberg, S., Von Karsa, L., Segnan, N., \& Van Delden, J. J. M. (2012). Determinants of successful implementation of population-based cancer screening programmes. European Journal of Cancer, 48(5), 743-748. doi:10.1016/j.ejca.2011.06.051

MacMahon, B. (2006). Epidemiology and the causes of breast cancer. International Journal of Cancer. doi:10.1002/ijc.21404

Malin, A. S., Qi, D., Shu, X. O., Gao, Y. T., Friedmann, J. M., Jin, F., \& Zheng, W. (2003). Intake of fruits, vegetables and selected micronutrients in relation to the risk of breast cancer. International Journal of Cancer, 105(3), 413-418. doi:10.1002/ijc.11088

Marmot, M. G., Altman, D. G., Cameron, D. a, Dewar, J. a, Thompson, S. G., \& Wilcox, M. (2013). The benefits and harms of breast 
cancer screening: an independent review. British Journal of Cancer, 108(11), 2205-40. doi:10.1038/bjc.2013.177

Maxwell Parkin, D., Bray, F., Ferlay, J., \& Pisani, P. (2001). Estimating the world cancer burden: Globocan 2000. International Journal of Cancer. doi:10.1002/ijc.1440

McDonald, J. T., \& Sherman, A. (2010). Determinants of mammography use in rural and urban regions of Canada. Canadian Journal of Rural Medicine: The Official Journal of the Society of Rural Physicians of Canada = Journal Canadien de La Medecine Rurale : Le Journal Officiel de La Societe de Medecine Rurale Du Canada, 15(2), 52-60.

McMenamin, M., Barry, H., Lennon, A. M., Purcell, H., Baum, M., Keegan, D., ... Mulcahy, H. (2005). A survey of breast cancer awareness and knowledge in a Western population: Lots of light but little illumination. European Journal of Cancer. doi:10.1016/j.ejca.2004.11.015

Min, H. Do, Sang, S. L., Jung, Y. K., Pa, J. J., \& Min, H. L. (2007). Fruits, vegetables, soy foods and breast cancer in pre- and postmenopausal korean women: A case-control study. International Journal for Vitamin and Nutrition Research, 77(2), $130-141$. doi:10.1024/0300-9831.77.2.130

Mohiuddin, M., Gafur, M. A., Karim, M. R., Khan, S. A., Hoque, M. M., Islam, M. S., ... M.S., A. (2012). Clinicopathological stages of carcinoma breast patient. Mymensingh Medical Journal : MMJ, 21(2), 238-245. Retrieved from http://www.embase.com/search/ results?subaction=viewrecord\&from=export\&id=L365813295lnhttp://sfx.library.uu.n//utrecht?sid=EMBASE\&issn=10224742\&id=d oi:\&atitle=Clinicopathological+stages+of+carcinoma+breast+patient.\&stitle=Mymensingh+Med+J\&title=Mymensingh+

O’Malley, A. S., Kerner, J., Johnson, A. E., \& Mandelblatt, J. (1999). Acculturation and breast cancer screening among Hispanic women in New York City. American Journal of Public Health, 89(2), 219-227. doi:10.2105/AJPH.89.2.219

Othman, A., Ahram, M., Obeidat, R., Obeidat, N., \& Tarawneh, M. (2013). Barriers for mammography among non-adherent women in Jordan: A national survey. Life Science Journal, 10(4), 2268-2274.

Özaras, G., Durualp, E., Civelek, F. E., Gül, B., \& Ünsal, M. (2010). Analysis of breast self-examination training efficiency in women between 20-60 years of age in Turkt. Asian Pacific Journal of Cancer Prevention, 11(3), 799-802.

Peintinger, F., Reitsamer, R., Stranzl, H., \& Ralph, G. (2003). Comparison of quality of life and arm complaints after axillary lymph node dissection vs sentinel lymph node biopsy in breast cancer patients. British Journal of Cancer, 89(4), 648-652. doi:10.1038/sj.bjc.6601150

Sandhu, D. S., Sandhu, S., Karwasra, R. K., \& Marwah, S. (2010). Profile of breast cancer patients at a tertiary care hospital in north India. Indian J Cancer, 47(1), 16-22. doi:10.4103/0019-509X.58853

Schmid-Buchi, S., Halfens, R. J., Muller, M., Dassen, T., \& van den Borne, B. (2013). Factors associated with supportive care needs of patients under treatment for breast cancer. Eur J Oncol Nurs, 17(1), 22-29. doi:10.1016/j.ejon.2012.02.003

Schootman, M., \& Jeffe, D. B. (2003). Identifying Factors Associated with Disability-Related Differences in Breast Cancer Screening (United States). Cancer Causes \& Control, 14(2), 97-107. doi:10.2307/3553622

Shack, L., Jordan, C., Thomson, C. S., Mak, V., \& Møller, H. (2008). Variation in incidence of breast, lung and cervical cancer and malignant melanoma of skin by socioeconomic group in England. BMC Cancer, 8, 271. doi:10.1186/1471-2407-8-271

Shahnazi, M., \& Khalili, A. (2010). Breast cancer screening (breast self-examination, clinical breast exam, and mammography) in women referred to health centers in Tabriz, Iran. Indian Journal of Medical Sciences. doi:10.4103/0019-5359.97355

Shannon, J., Ray, R., Wu, C., Nelson, Z., Gao, D. L., Li, W., ... Thomas, D. (2005). Food and botanical groupings and risk of breast cancer: a case-control study in Shanghai, China. Cancer Epidemiology, Biomarkers \& Prevention : A Publication of the American Association for Cancer Research, Cosponsored by the American Society of Preventive Oncology, 14(1), 81-90.

Shin, K. R., Park, H. J., \& Kim, M. (2012). Practice of breast self-examination and knowledge of breast cancer among female university students in Korea. Nursing and Health Sciences, 14(3), 292-297. doi:10.1111/j.1442-2018.2012.00696.x

Smith, L. H., Dalrymple, J. L., Leiserowitz, G. S., Danielsen, B., \& Gilbert, W. M. (2001). Obstetrical deliveries associated with maternal malignancy in California, 1992 through 1997. In American Journal of Obstetrics and Gynecology (Vol. 184, pp. 1504-1513). doi:10.1067/mob.2001.114867

Smyer, T., \& Stenvig, T. E. (2007). Health Care for American Indian Elders: An Overview of Cultural Influences and Policy Issues. Home Health Care Management \& Practice. doi:10.1177/1084822307305380

Society, A. C. (2011). Cancer Facts \& Figures 2011. American Cancer Society. doi:10.3322/caac.20121

Story, H. L., Love, R. R., Salim, R., Roberto, a J., Krieger, J. L., \& Ginsburg, O. M. (2012). Improving outcomes from breast cancer in a low-income country: lessons from bangladesh. International Journal of Breast Cancer, 2012(Figure 1), 423562. doi:10.1155/ 2012/423562

Stuckey, A. (2011). Breast cancer: epidemiology and risk factors. Clinical Obstetrics and Gynecology, 54(1), 96-102. doi:10.1097/GRF. Ob013e3182080056

Suh, M. A. B., Atashili, J., Fuh, E. A., \& Eta, V. A. (2012). Breast self-examination and breast cancer awareness in women in developing countries: a survey of women in Buea, Cameroon. BMC Research Notes, 5, 627. doi:10.1186/1756-0500-5-627

Terry, P., Terry, J. B., \& Wolk, A. (2001). Fruit and vegetable consumption in the prevention of cancer: an update. J Intern Med, 250(4), 280-290.

Todd, A., \& Stuifbergen, A. (2012). Breast cancer screening barriers and disability. Rehabilitation Nursing, 37(2), 74-79. doi:10.1002/ RNJ.00013

Uk, I., \& Cancer, B. (2012). The benefits and harms of breast cancer screening: an independent review. Lancet, 380(9855), $1778-86$. doi:10.1016/S0140-6736(12)61611-0

Weiss, N. S. (2011). The analysis of case-control studies of the efficacy of screening for recurrence of cancer. Journal of Clinical 
Epidemiology. doi:10.1016/j.jclinepi.2010.07.013

Williams, P. T. (2013). Breast cancer mortality vs. exercise and breast size in runners and walkers. PLOS ONE, 8(12). doi:10.1371/ journal.pone.0080616

World Cancer Research Fund, A. I. for C. R. (2007). Food, Nutrition, Physical Activity, and the Prevention of Cancer: a Global Perspective. Washington DC: AICR.

Claire E Wright., Michelle Harvie., Anthony Howell., D Gareth Evans., Nick Hulbert-Williams., \& Louise S Donnelly. (2015). Beliefs about weight and breast cancer: an interview study with high risk women following a 12 month weight loss intervention.

Zhao, H., \& Kanda, K. (2000). Translation and validation of the standard Chinese version of the EORTC QLQ-C30. Quality of Life Research, 9(2), 129-137. doi:10.1023/A:1008981520920

Zotti, P., Lugli, D., Vaccher, E., Vidotto, G., Franchin, G., \& Barzan, L. (2000). The EORTC quality of life questionnaire-head and neck 35 in Italian laryngectomized patients. Quality of Life Research, 9(10), 1147-1153. doi:10.1023/A:1016674507150 